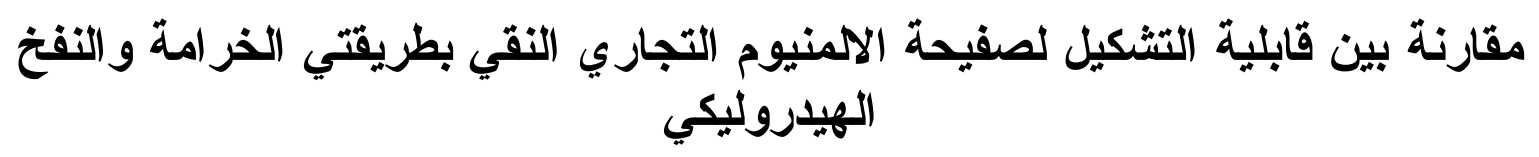

$$
\text { لقمان خليل حيدر }
$$

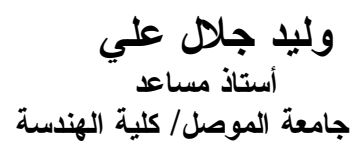

الخلاصة

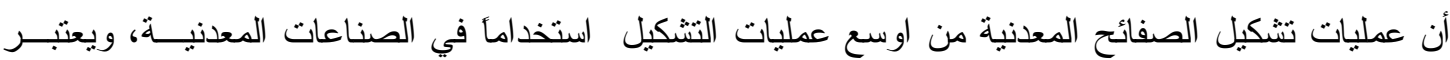

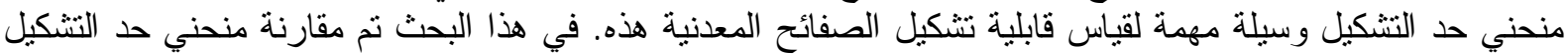

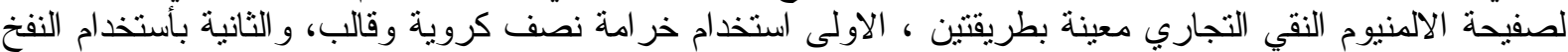

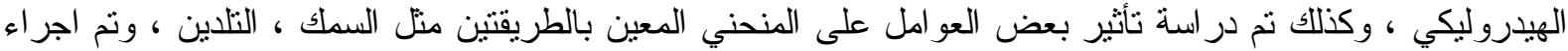
المقارنة بين المنحنيات المعينة بكلا الطريقتين.

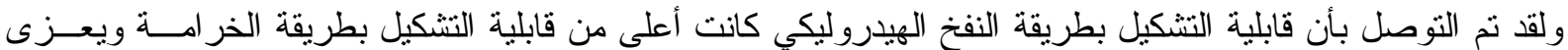

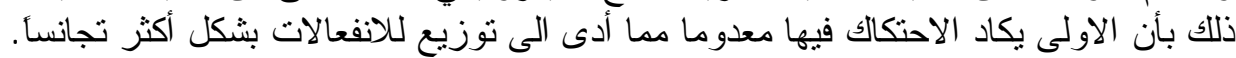

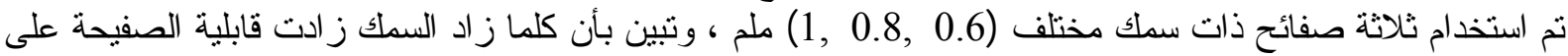

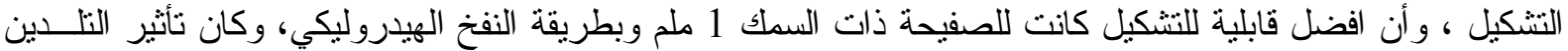
على تحسين قابلية التشكيل أفضل عند استخدام النفخ الهيدروليكي.

\title{
A Comparison of Formability of Commercial Pure Aluminum Sheet by Using Punch and Hydraulic Bulging
}

\author{
W. J. Ali \\ University of Mosul/Mech. Dep.
}

\author{
L. Kh. Haider, Eng. \\ Technical Inst./ Mosul
}

\begin{abstract}
Abstruct
The sheet meal forming are the most widely used in the metal industries. The forming limit curve(FLC) is considered as the important mean of measuring the formability of sheet metal. In this work the FLCs of pure Aluminum sheets, determined firstly by using hemispherical punch and die, and secondly by bulging, were compared. Also the effect of some factors on the FLC, such as thickness and annealing were studied, and a comparison was made between the FLCs determined by the two methods. It was shown that the formability determined by bulging is higher and this is due to the absence of friction during forming which lead to a more uniform strain distribution. Three sheets thickness were used $(1,0.8$ and 0.6$) \mathrm{mm}$. It was found that the formability is increased with thickness in both methods. The best formability was of the sheet of $1 \mathrm{~mm}$ thickness, deformed by bulging. Annealing improved formability and the better improvement was by bulging
\end{abstract}

Keyword : Aluminum sheet - Forming limit diagram - Hydraulic Bulging 


\section{Al-Rafidain Engineering $\quad$ Vol.18 $\quad$ No.2 $\quad$ April 2010}

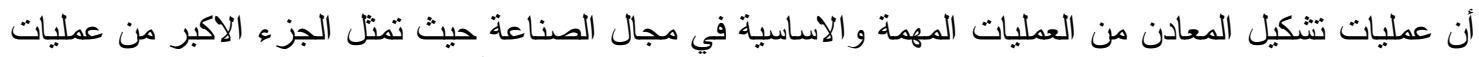

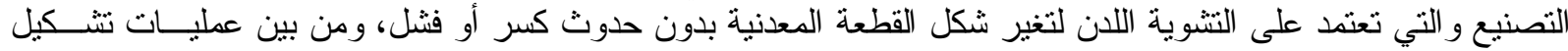

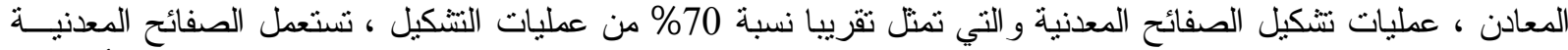

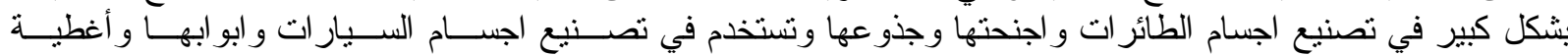
المحركات.

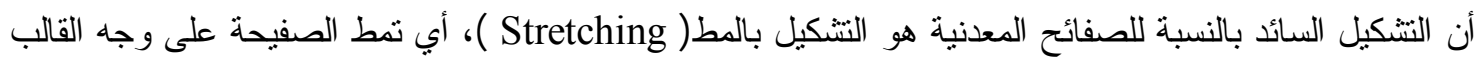

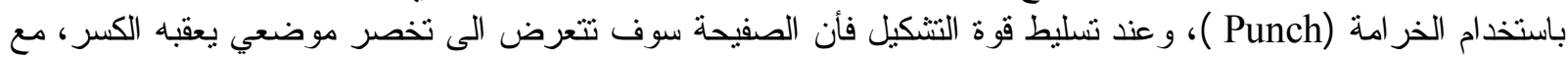

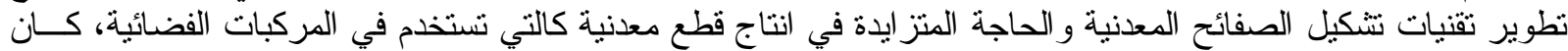
استخدام طريقة تشكيل الصفائح المعدنية بالنفخ الهيدروليكي (Hydraulic Bulging ) هي الطريقة الملائمة و الملبية لحاجة

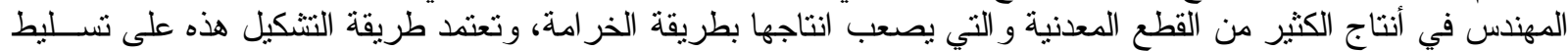

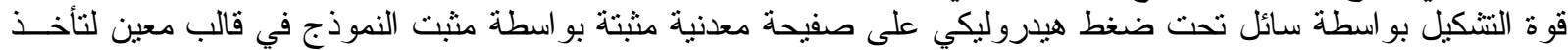

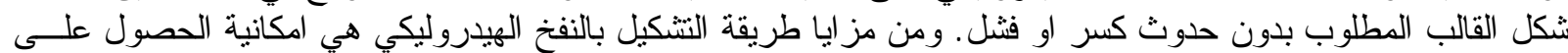

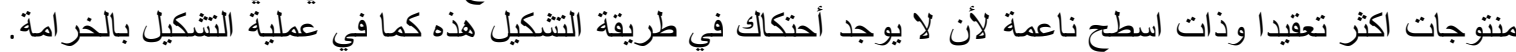

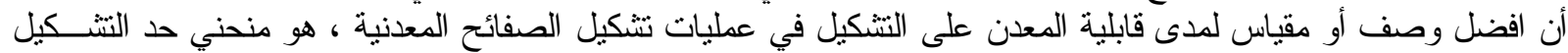
(Forming Limit Curve)

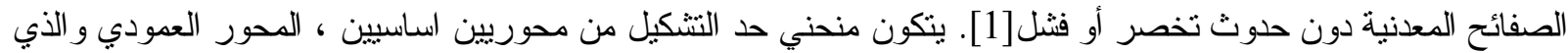

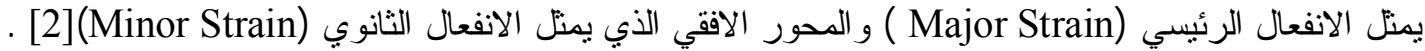

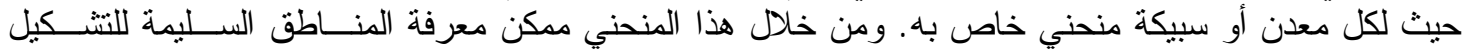

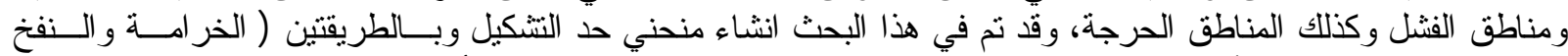
الهيدروليكي) ونم در اسة نأثير السمك و عملية التلدين على هذي المنحنيات المعينةٍ بالطريقتين أعلاه.

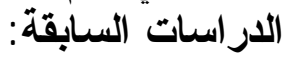

أن أول من ساهم في بناء منحني حد التشكيل هما الباحثــان (Keeler \& Backfon 1963) [3] ، حبــث قــام

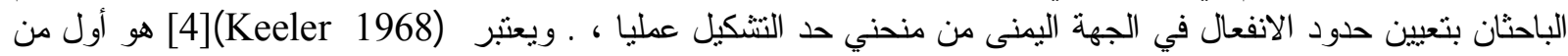

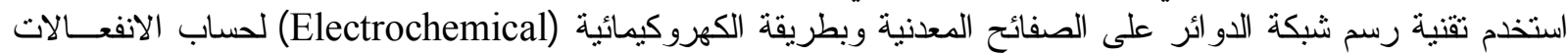

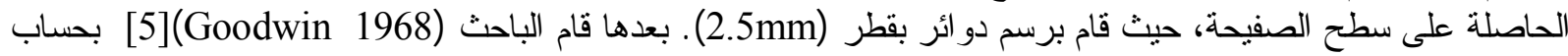

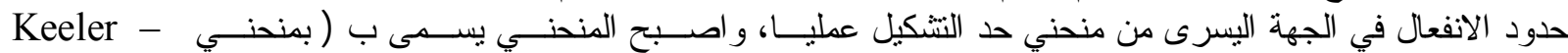
Goodwin

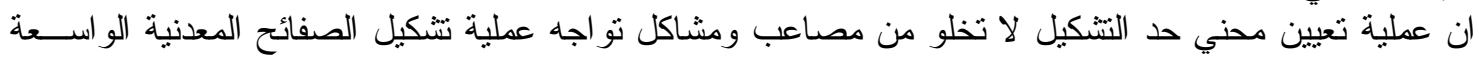

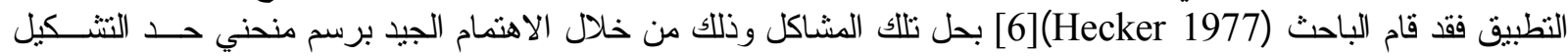

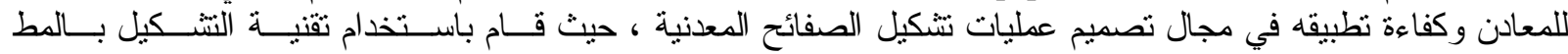
(Stretch Forming) العرض ومتساوية في الطول لغرض تعيين منحني حد التشكيل بكل مسار اته عمليا ولصفائح معدنية كثيرة و هذه المنحنيـات

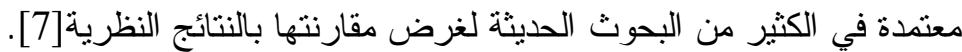

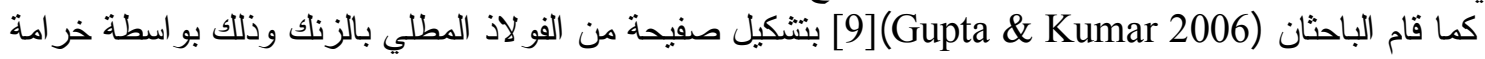

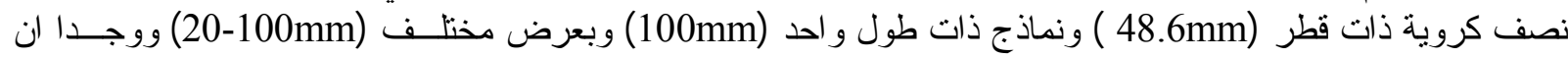

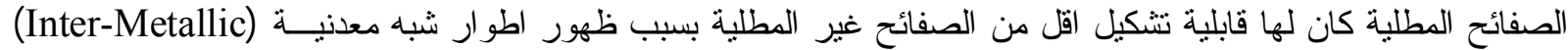
هشة بين الحديد و الزنك و التي تعمل على تقليل من قابلية التنكيل. كذللك قام الباحثان(10) (10) بيناء

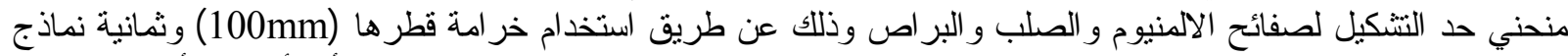

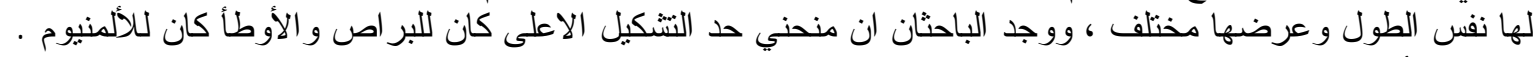

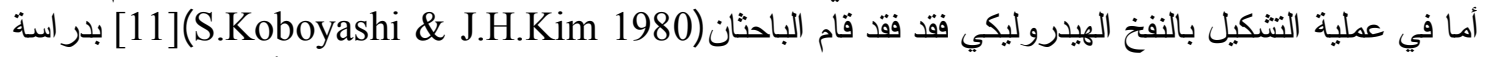

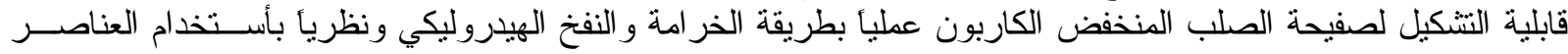

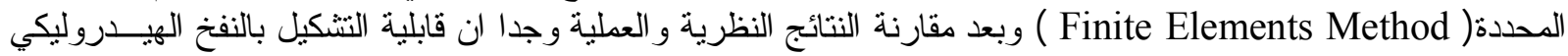




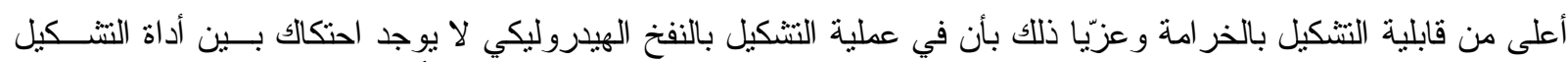

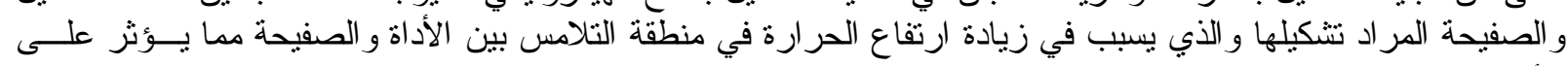

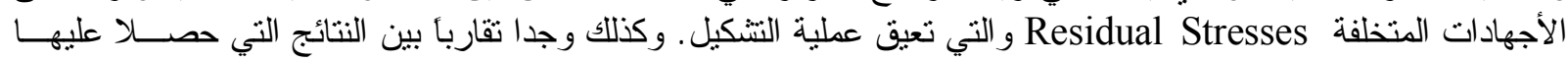
عمليا مع النتائج الني حصلا علئة النيا بالطريقة النظرية.

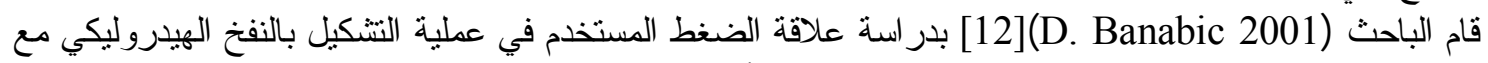

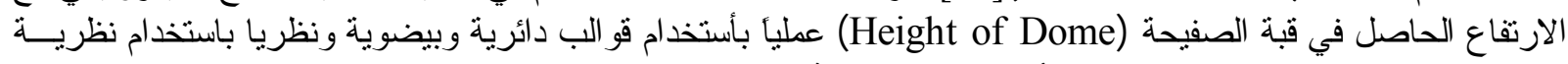

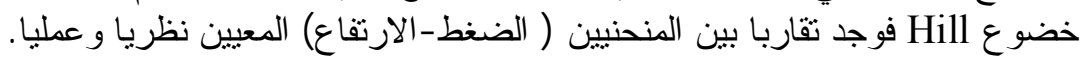

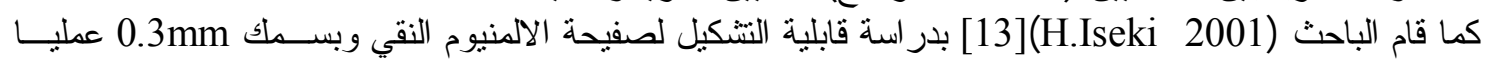

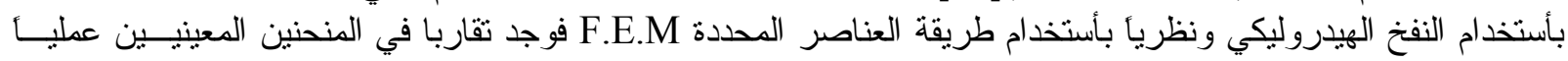

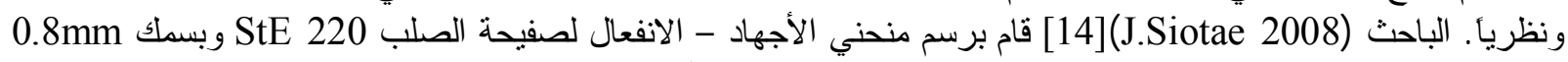

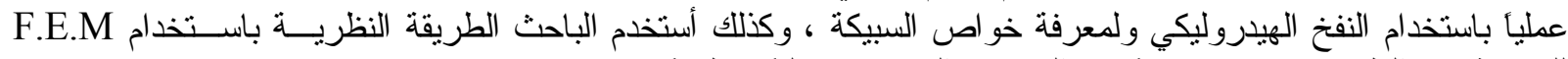
للمقارنة بين الطريقتين فوجد تقاربأ بين المنحنين المعينيين عملياً ونظرياً

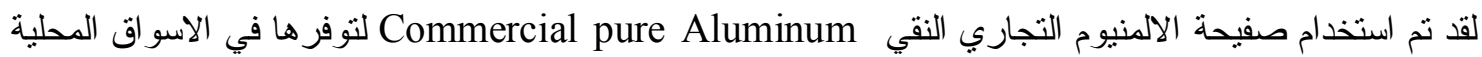

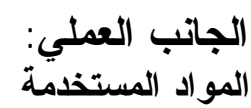
وكذلك لكثرة استخدامها في بلدنا ولرخص ثمنها ونتم تحلَّليا كيميائيا وكما موضحة في الجدول التالي:

\section{الجدول ( 1): التحليل الكيميائي لصفيحة الامنيوم التجاري النقي}

\begin{tabular}{|c|c|c|c|c|c|c|c|c|}
\hline \multicolumn{10}{|c|}{ Chemical Composition } \\
\hline Elements & $\mathrm{Fe} \%$ & $\mathrm{Mn} \%$ & $\mathrm{Cr} \%$ & $\mathrm{Si} \%$ & $\mathrm{Ni} \%$ & $\mathrm{Ti} \%$ & $\mathrm{Cu} \%$ & $\mathrm{Al} \%$ \\
\hline Percentages & 0.6 & 0.015 & 0.006 & 0.2 & 0.001 & 0.01 & 0.11 & $\mathrm{Rem}$. \\
\hline
\end{tabular}

في عملية التشكيل بالمط تم استخدام خر امة نصف كروية ذات قطر (50 ملم ) مع قالب دائري ومثبت للنموذج كمــا فـي

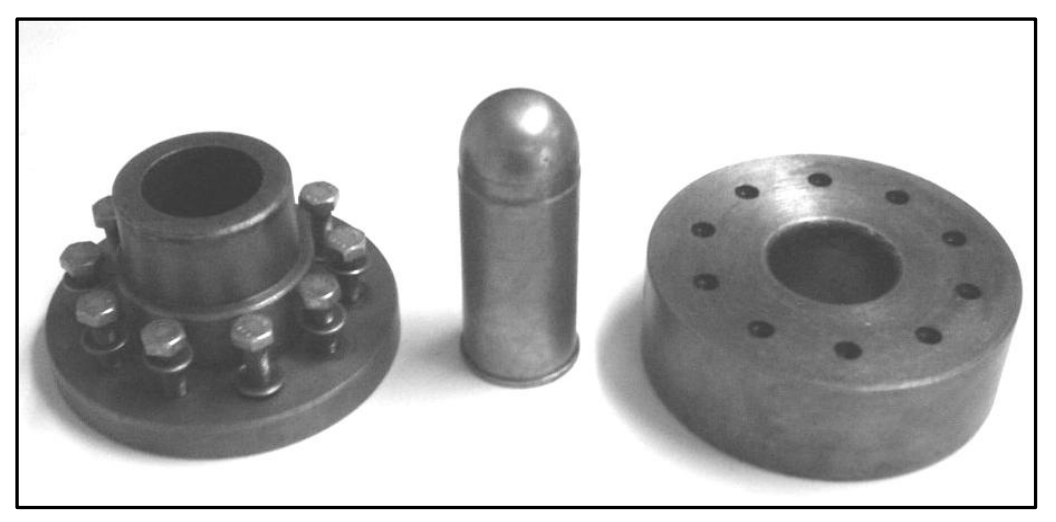

[15] الثكل(1)

$$
\text { الثكل(1): رسما تجميعيأ وصورة توضيحية للخر امة و القالب }
$$

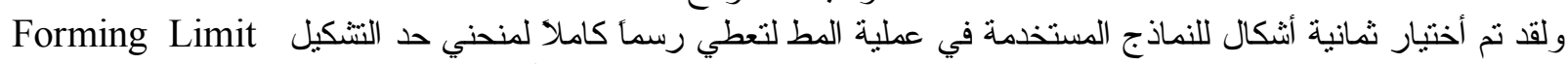

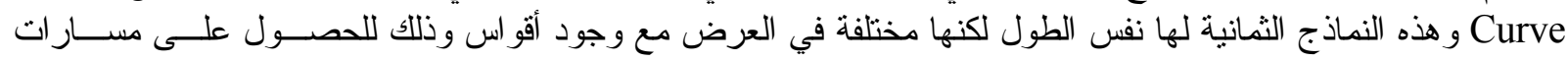


Al-Rafidain Engineering $\quad$ Vol.18 No.2

April 2010

انفعال مختلفة (strain paths )، من مسار الثد أحادي المحور الى مسار المط ثنائي المحوريين المنساويين مرورأ بمسسار الانفعال المستوي وكما في الثكل (2):

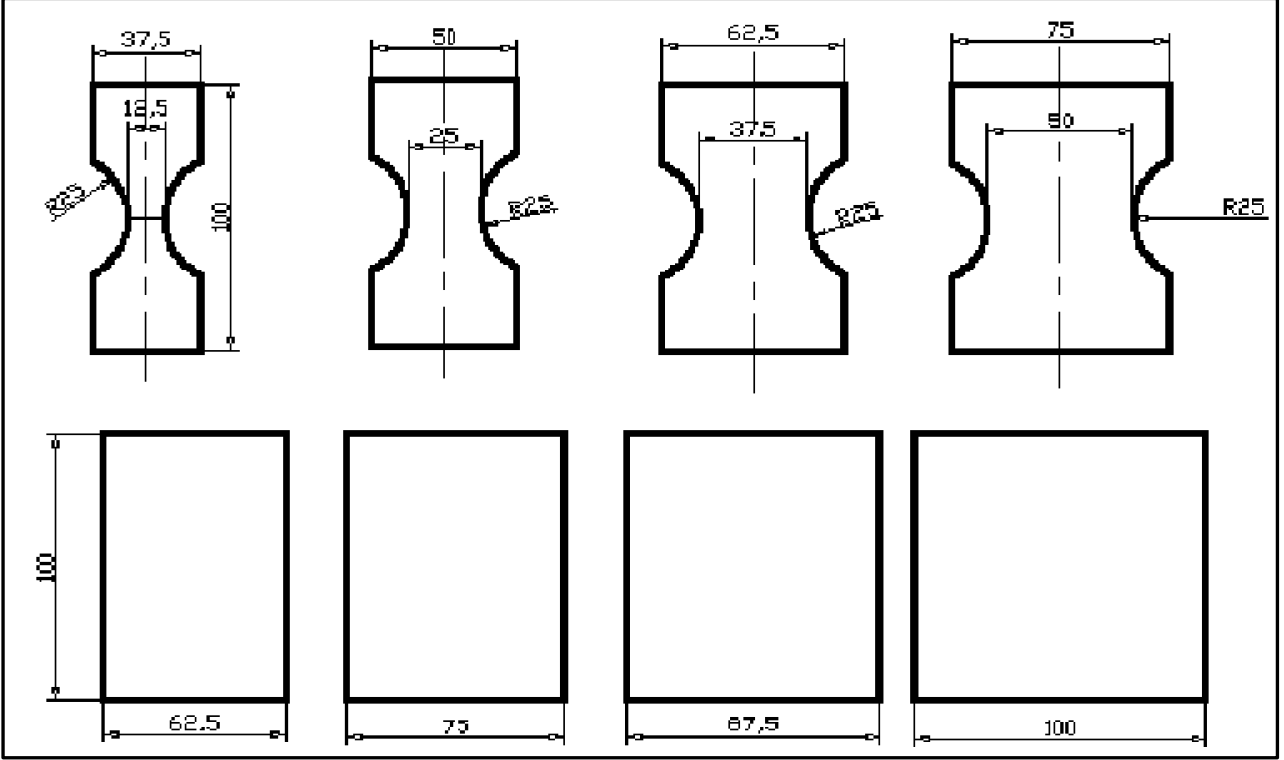

الثكل(2): اثكال و ابعاد النماذج الثمانية و المستخدمة في عملية التشكيل بالخر امة

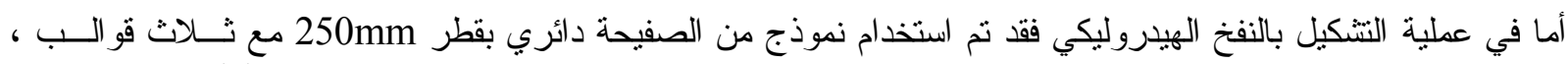

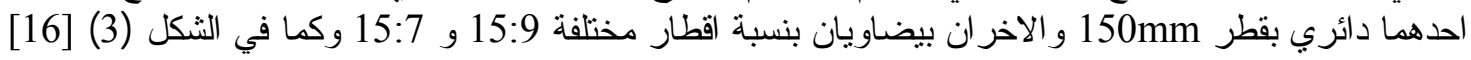
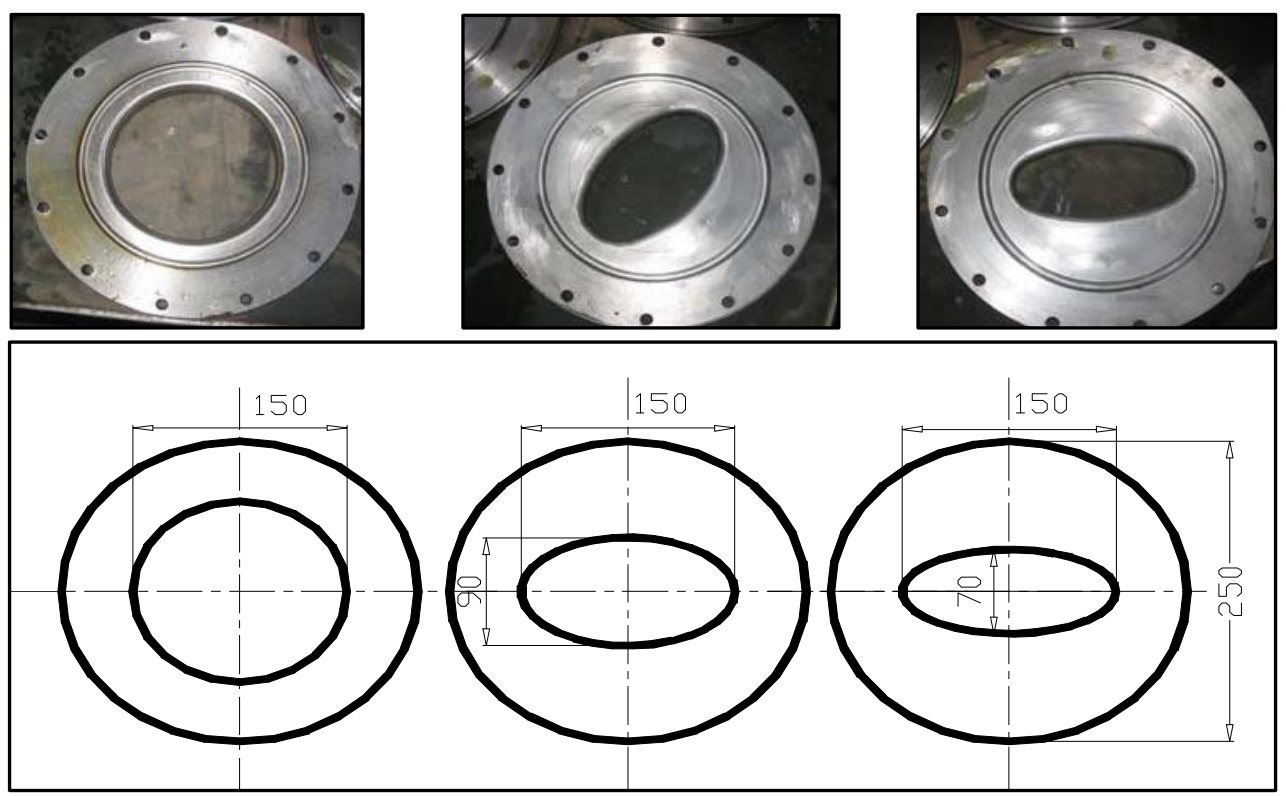

الثكل (3) : القو الب الثلاثة المستخدمة في البحث[16]

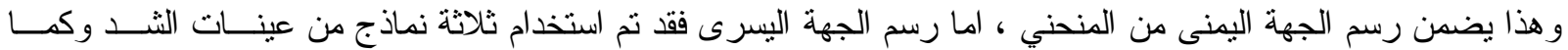

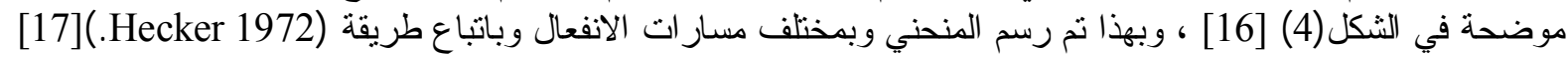



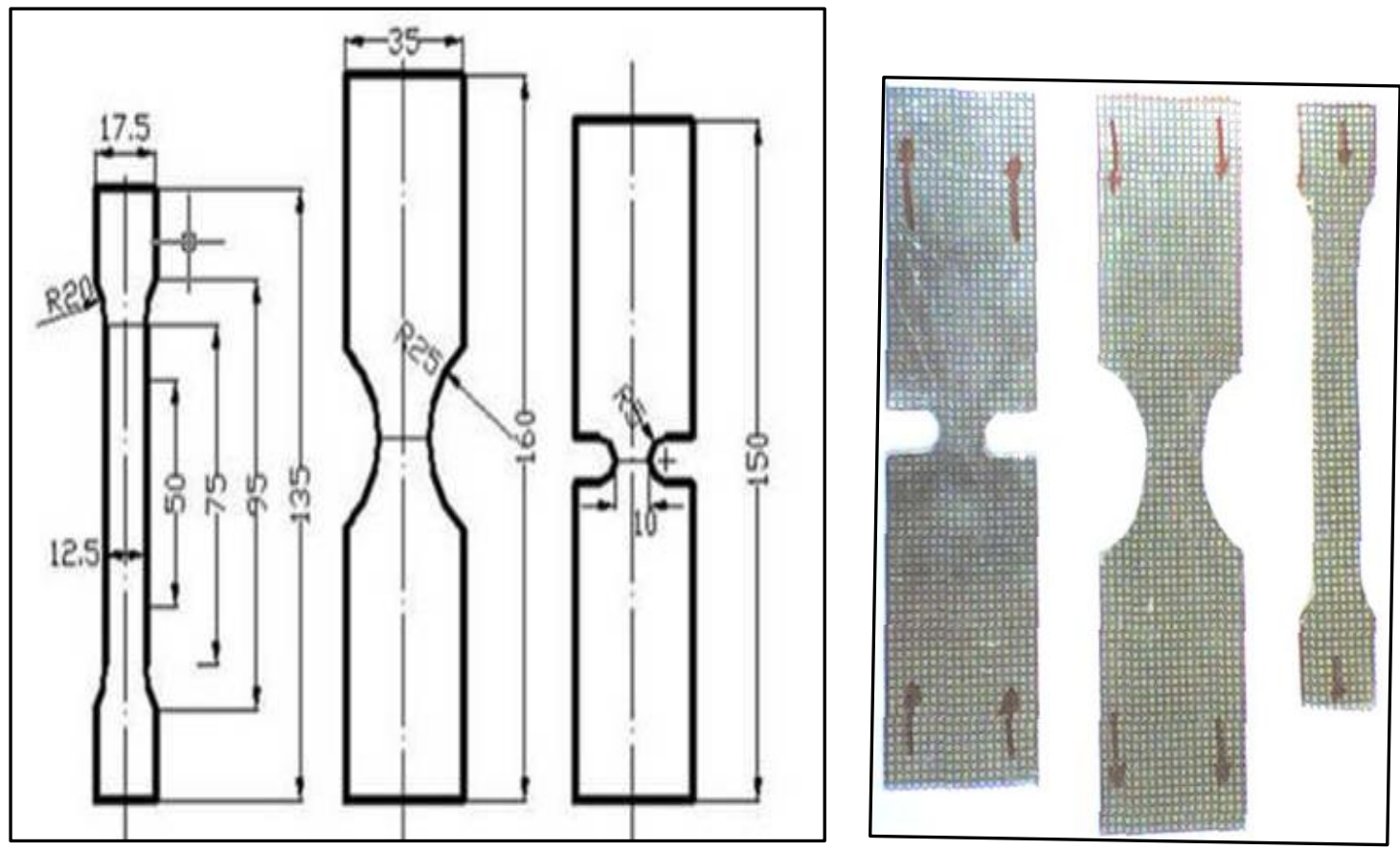

الثكل (4): النماذج الثثلاثة لعينات الثد لرسم الجهة اليسرى

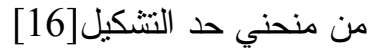

عملية التشكيل بالخر امة:

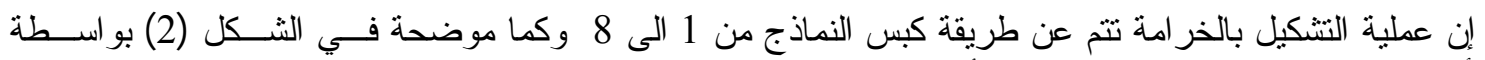

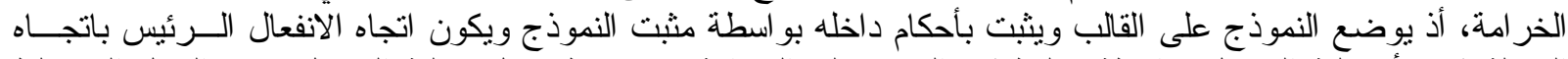

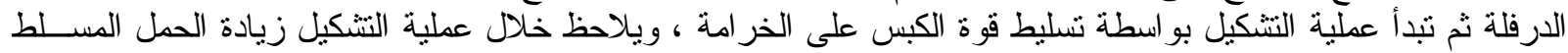

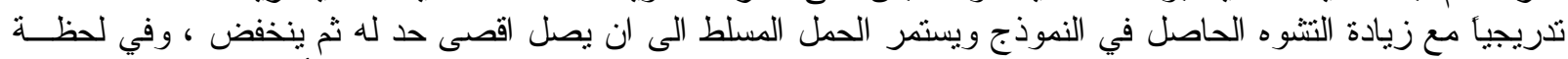

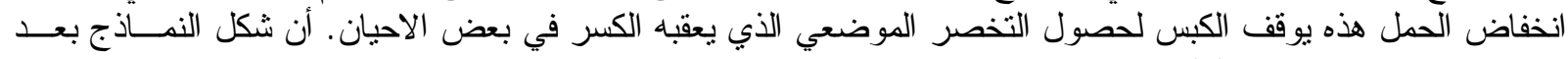

النتكيل موضح في الثكل (5)

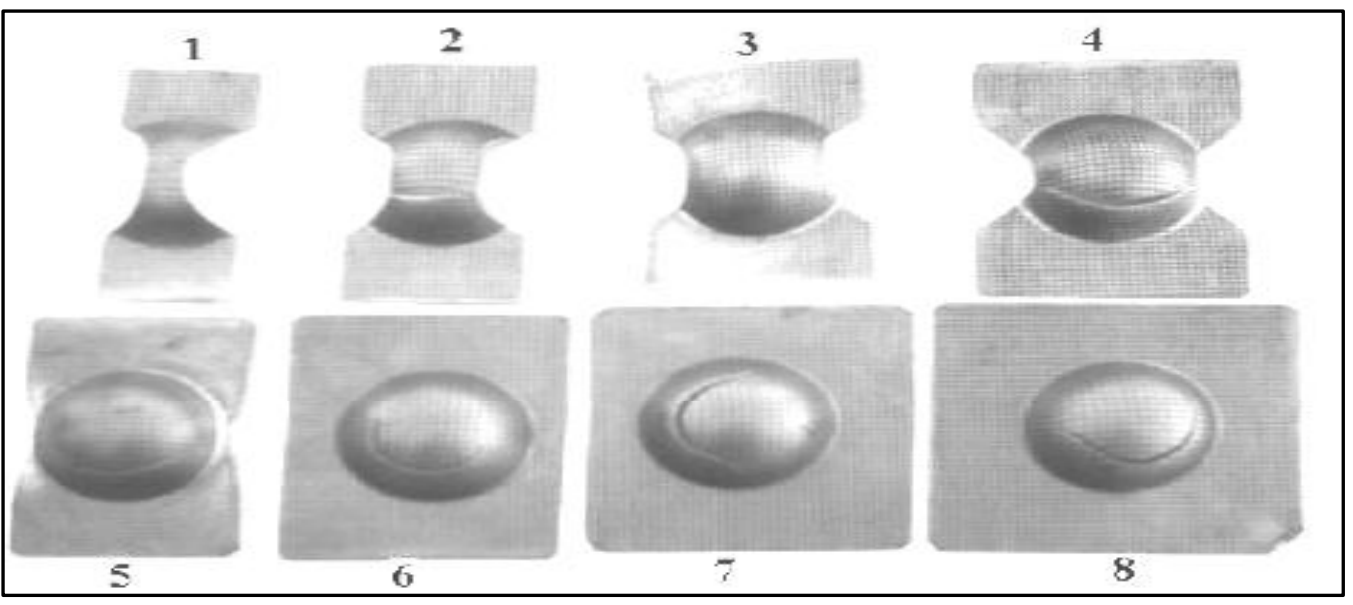

الثكل(5) : صورة فونوغر افية للنماذج الثمانية و المشكلة بعملية النتكيل بالخر امة 


\section{Al-Rafidain Engineering $\quad$ Vol.18 $\quad$ No.2 $\quad$ April 2010}

عميلةٌ التشكيل بالنفخ الهيلروليكي:

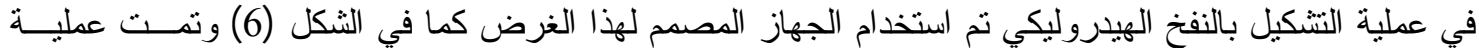

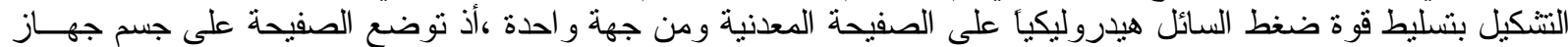

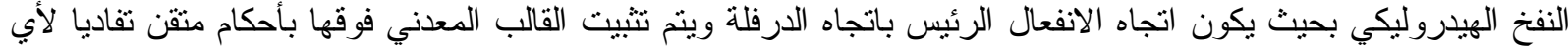

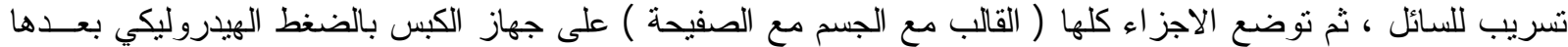

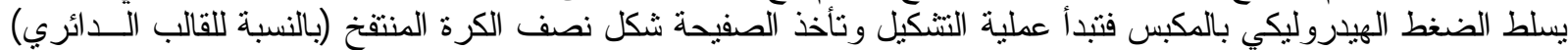

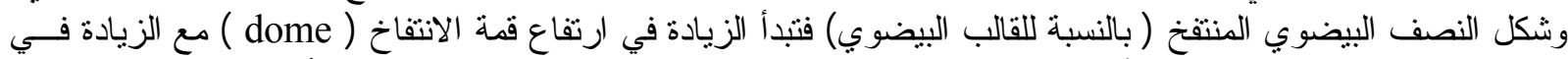

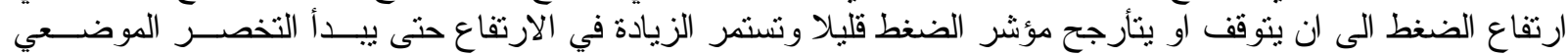

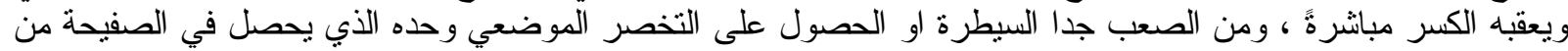

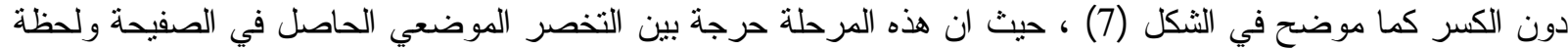

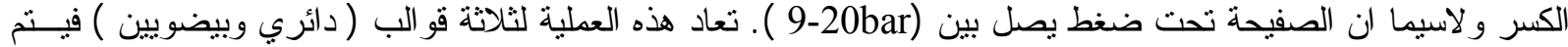

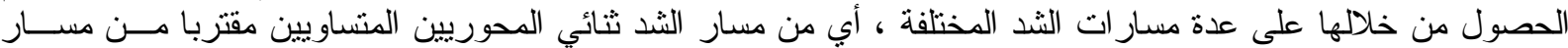

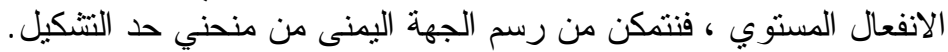

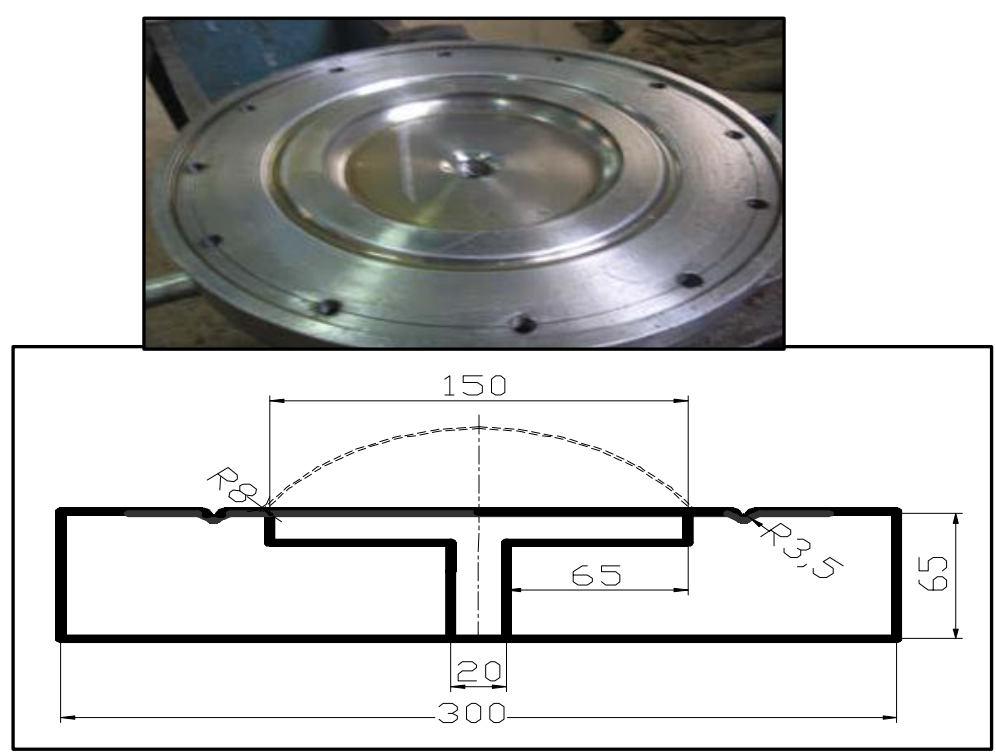

الثكل (6) صورة ورسم توضيحي للجهاز المستخدم في عملية النتكيل بالنفخ الهيدروليكي

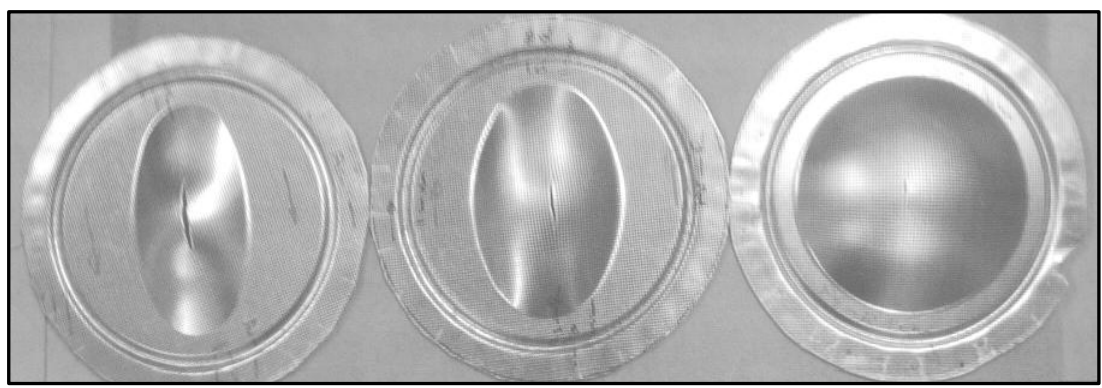

الثكل (7): صورة فوتوغر افية للنماذج الثثلاثة المشكلة في عملية التشكيل بالنفخ الهيدروليكي لرسم الجهة اليمنى من منحني حد النتكيل وبيان منطقة الكسر فئنها 


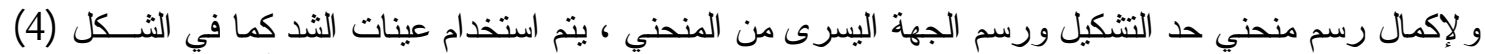

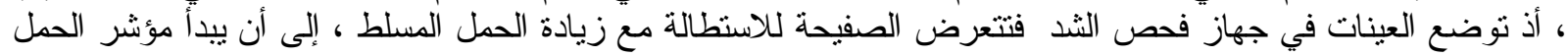

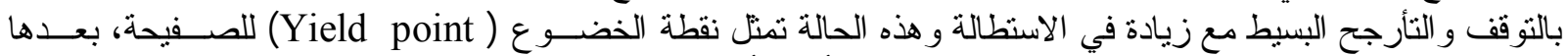

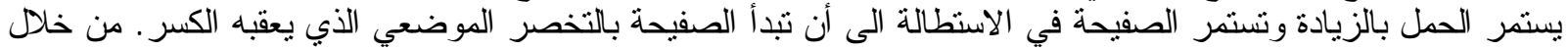

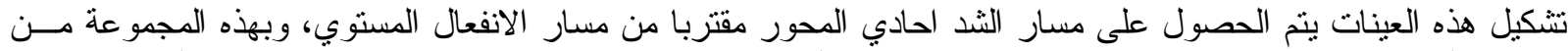

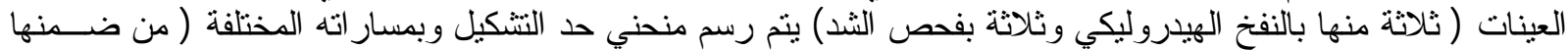

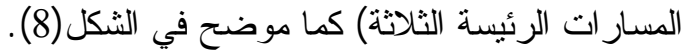

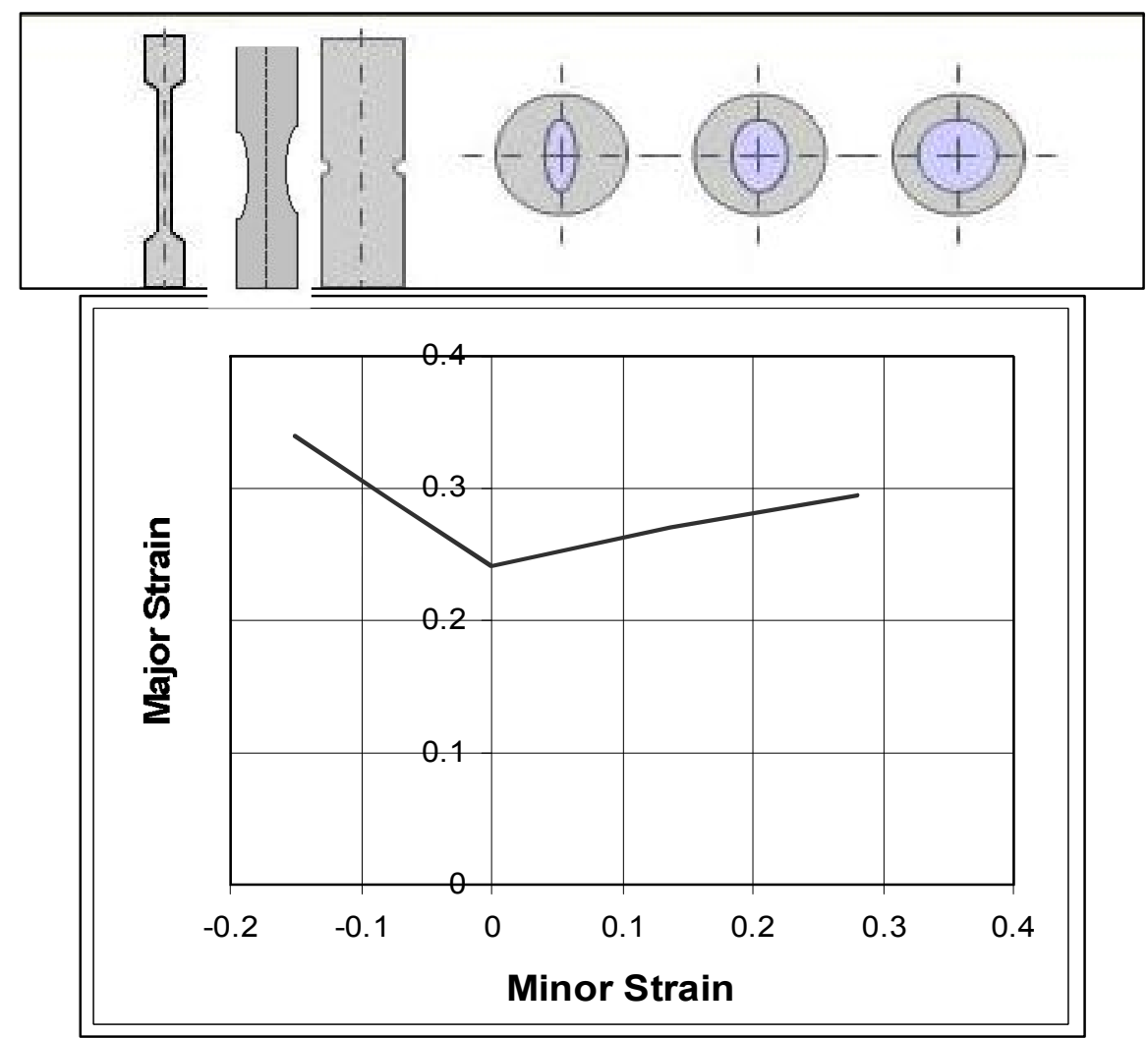

الثكل(8): منحني حد التشكيل المرسوم بعملية النتكيل بالنفخ الهيدروليكي(الجزء الأيمن) وبنماذج الثند الخاصة (الجزء الأيسر )

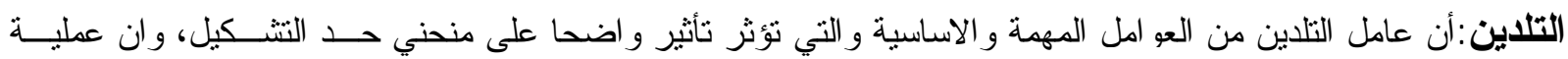

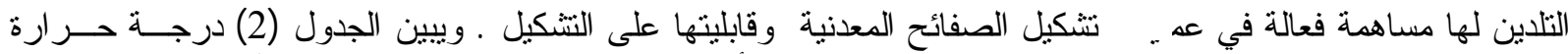

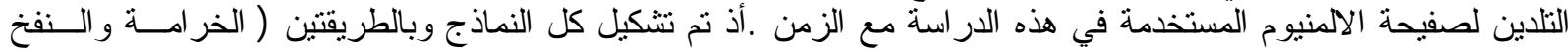
العيدروليكي) ونم تعيين منحني حد التشكيل ولكل سمك (1,0.8,0.6 mm).

الجدول (2):يبين درجة حرارة التلاين مع الزمن لصفيحة الامنيوم المستخدمة.

\begin{tabular}{|c|c|c|c|}
\hline Material & $\begin{array}{c}\text { Annealing } \\
\text { Material } \\
\text { Temperature (c }\end{array}$ & $\begin{array}{c}\text { Time of Heating } \\
\text { (min) }\end{array}$ & $\begin{array}{c}\text { Soaking Time } \\
\text { (min) }\end{array}$ \\
\hline Pure Aluminum & 275 & 15 & 10 \\
\hline
\end{tabular}




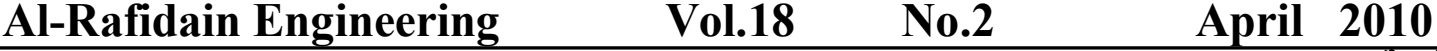

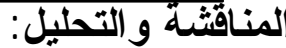

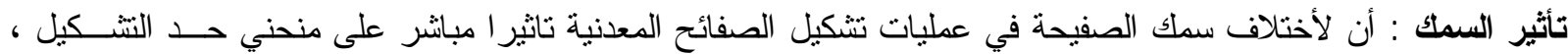

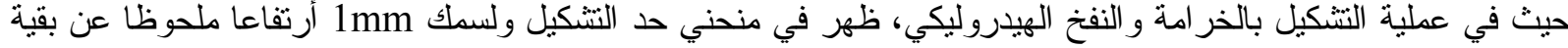

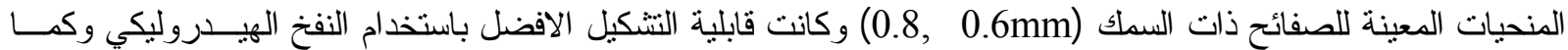
موضحة في الأشكال(9)،(10).

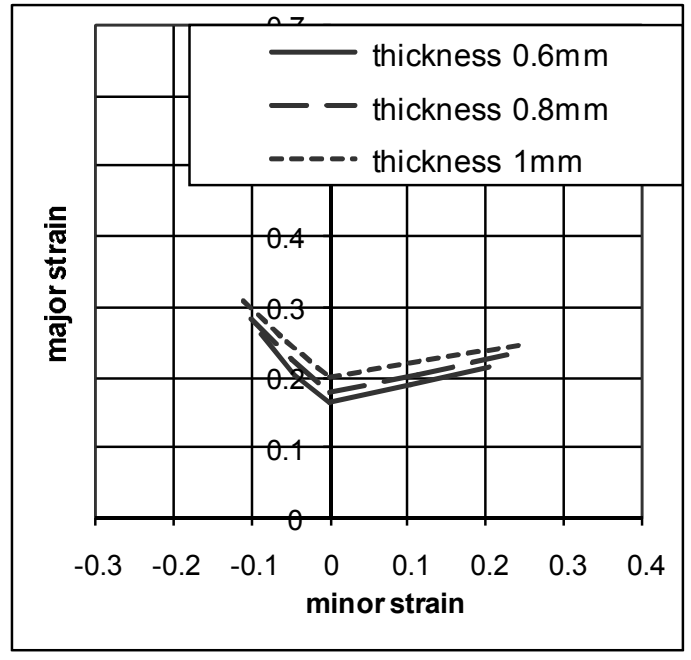

الثنكل (10): تأثير السمك على منحني حد التشكيل

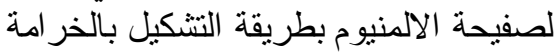

(As-Received) ملم، وكما مستلمة (0.6 ) 0.8,

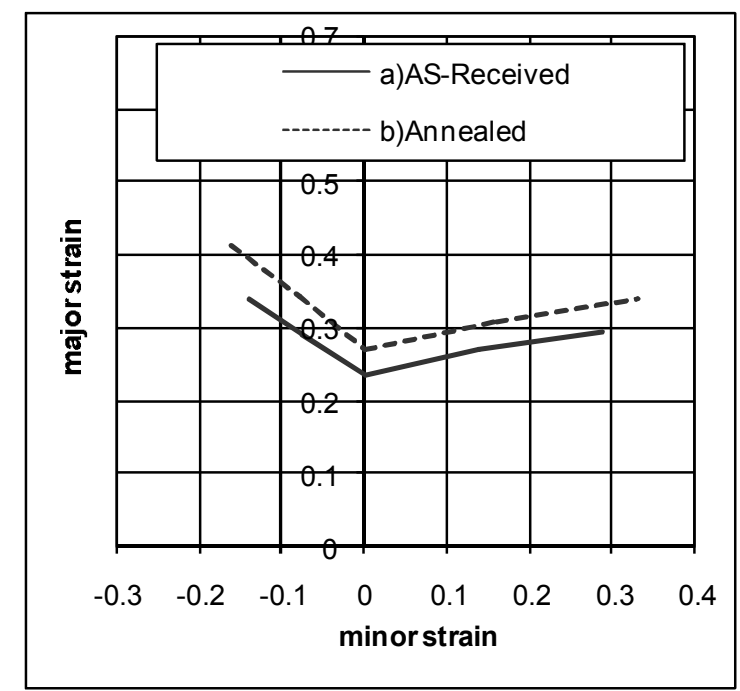

الثكل (11): مقارنة بين منحنيات حد التشكيل لصفيحة

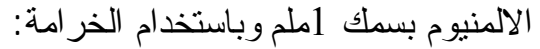

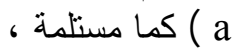

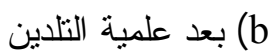

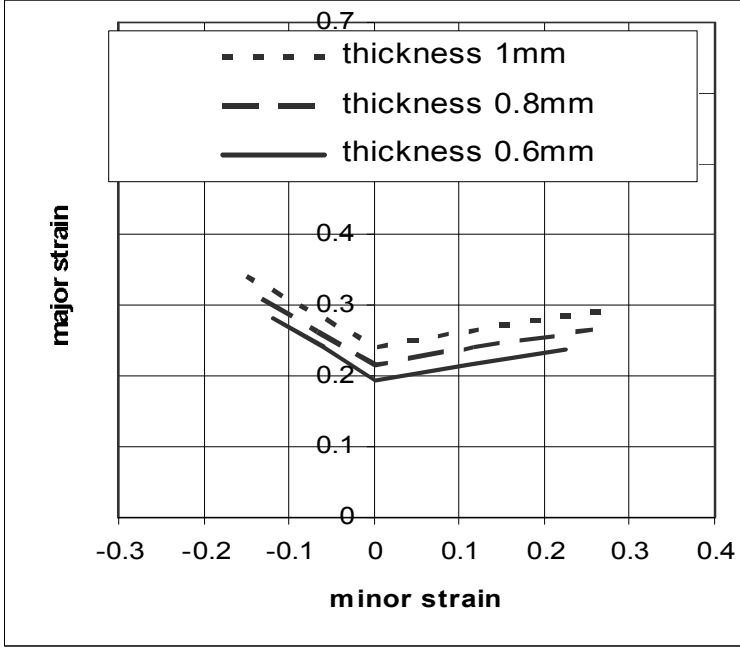

الثكل (9): تأثثير السمك على منحني حد التشكيل لصفيحة الالمنيو بطريقة النتكيل بالنفخ الهيدروليكي التيكي

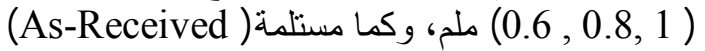

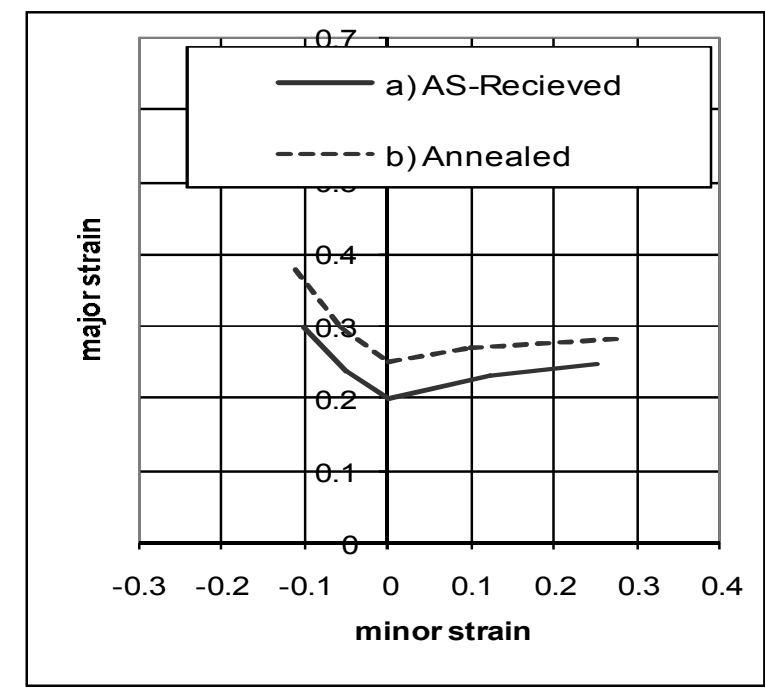

الثكل (12): مقارنة بين محنيات حد التثكيل لصفيحة الالمنيوم بسمكا ملمارنة ملم وباستخدام النفخ

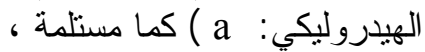

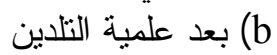


و على العموم يمكن القول بأنه كلما زاد سمك الصفيحة زادت قابلية التشكيل لتلك الصفيحة وهذا بسبب أن الانفعال $\varepsilon_{\mathrm{t}}=\ln \frac{\mathrm{t}}{\mathrm{t}_{\mathrm{o}}}$

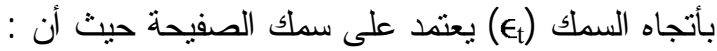

حيث كلما ز اد السمك t للصفيحة المستخدمة زادت قيمة الانفعال باتجاه السمك و أعطت مجال أكبر لعملية الترقيق وتــأخير

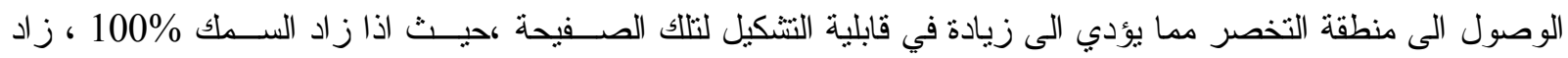

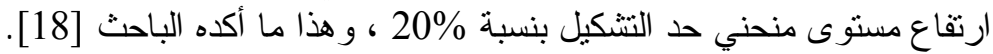

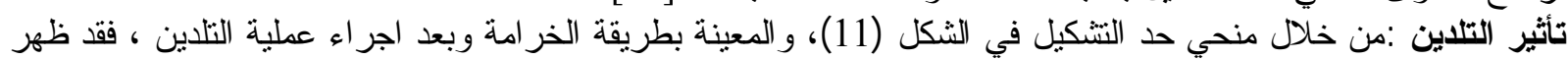

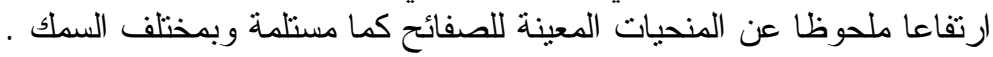

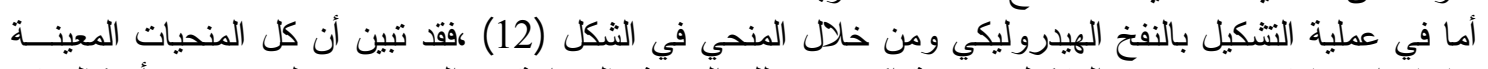

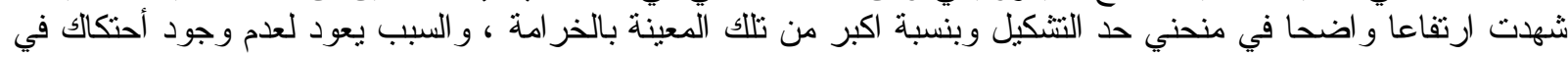

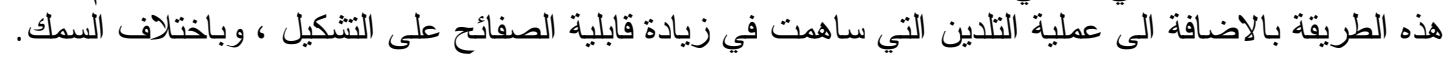

تأثثير الأحتكاتك : إن عامل الاحتكالك من اهم العو امل التي أهتم بها مهندسو النتكيل ، لأنه يؤدي دور أ مباشر أ ومهما فـي

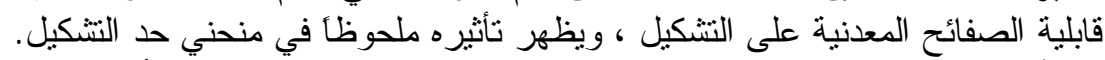

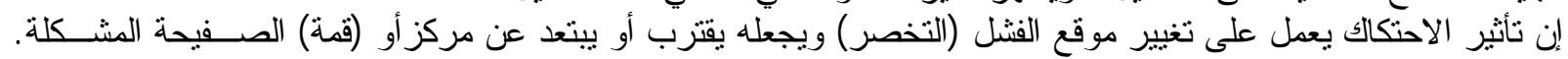

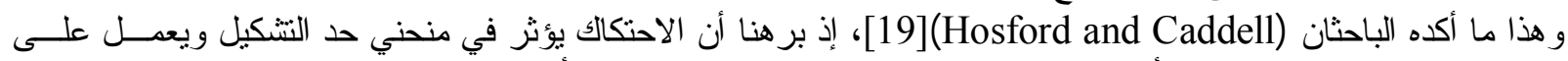

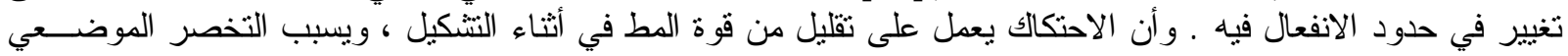
وفي هذه الدر اسة ولغرض معرفة تأثير الاحتكاك في منحني حد النتكيل ، فقد تم استخدام طريقة النتكيل بالخر امة

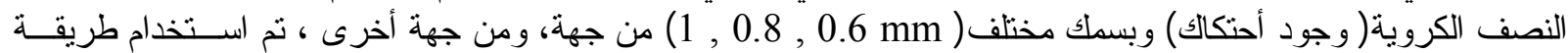

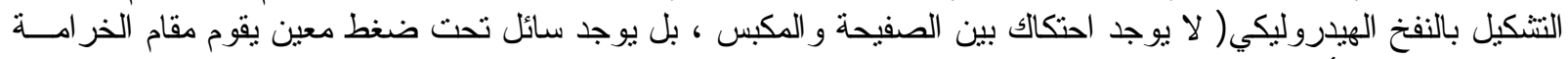

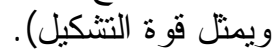

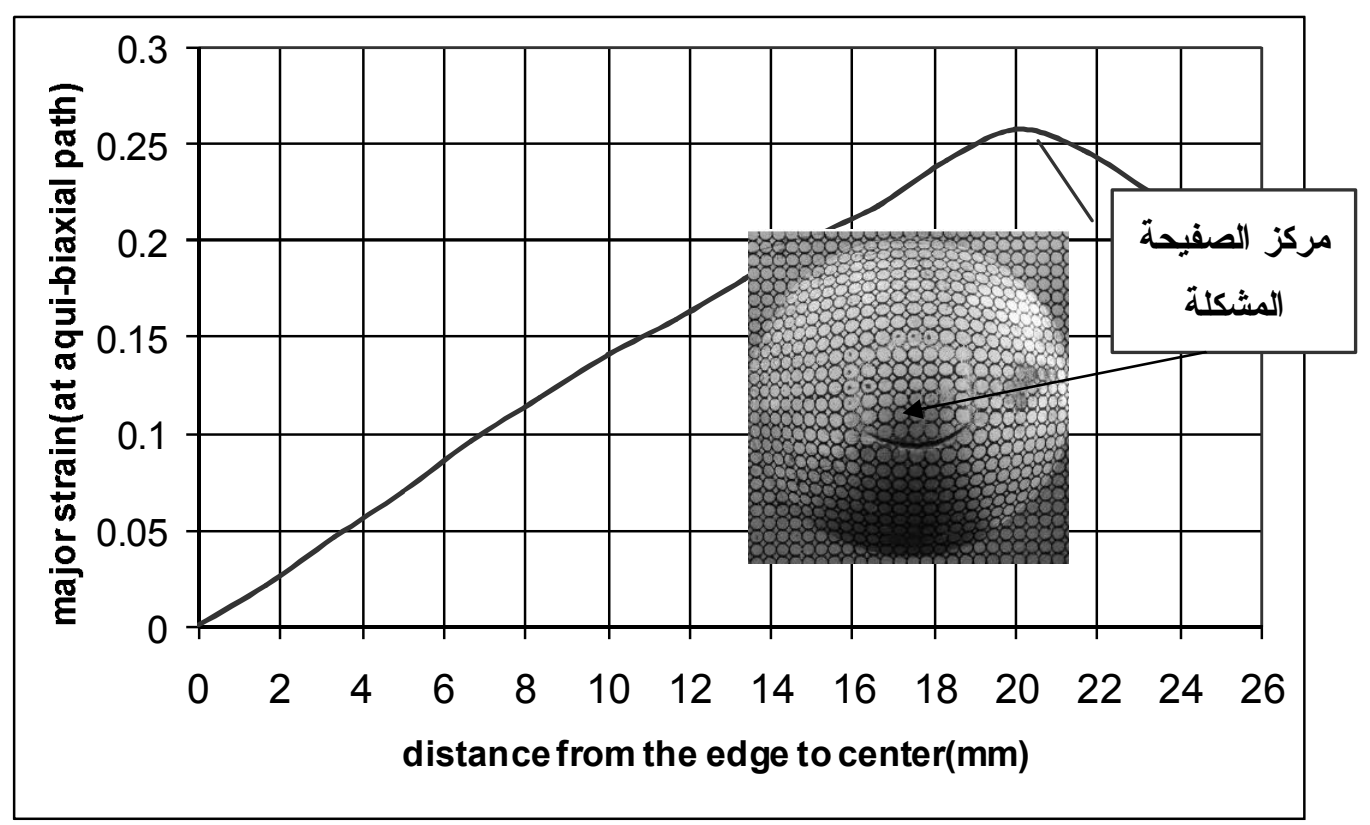

الثكل (13): نوزيع الانفعال الرئيس باتجاه مسار ثنائي المحورين المتساويين من الحافة

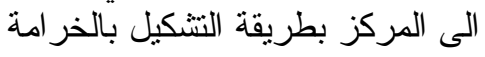




\section{Al-Rafidain Engineering $\quad$ Vol.18 $\quad$ No.2 $\quad$ April 2010}

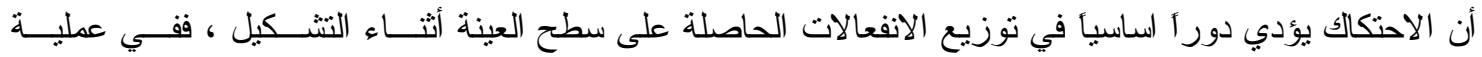

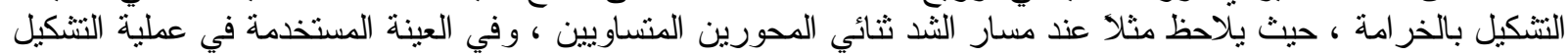

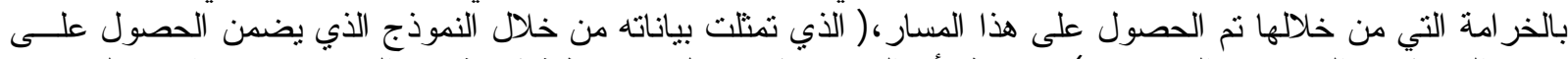

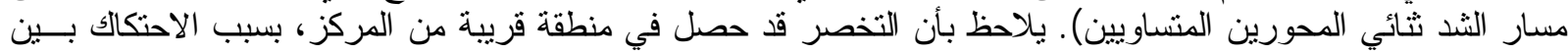

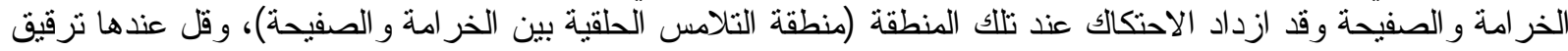

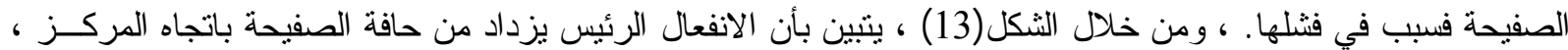

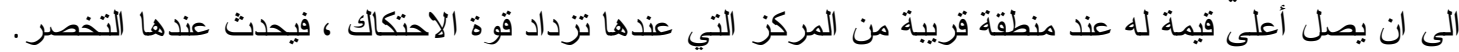

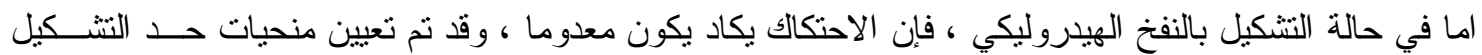

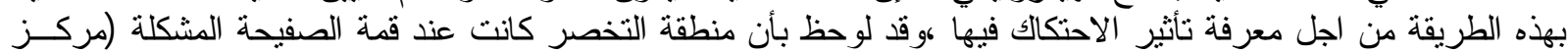

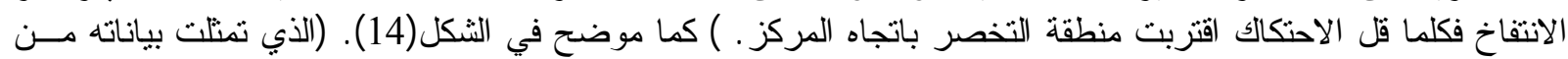

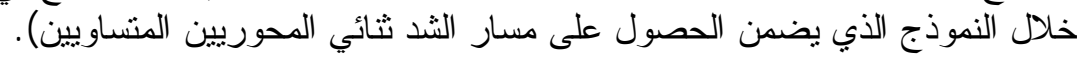

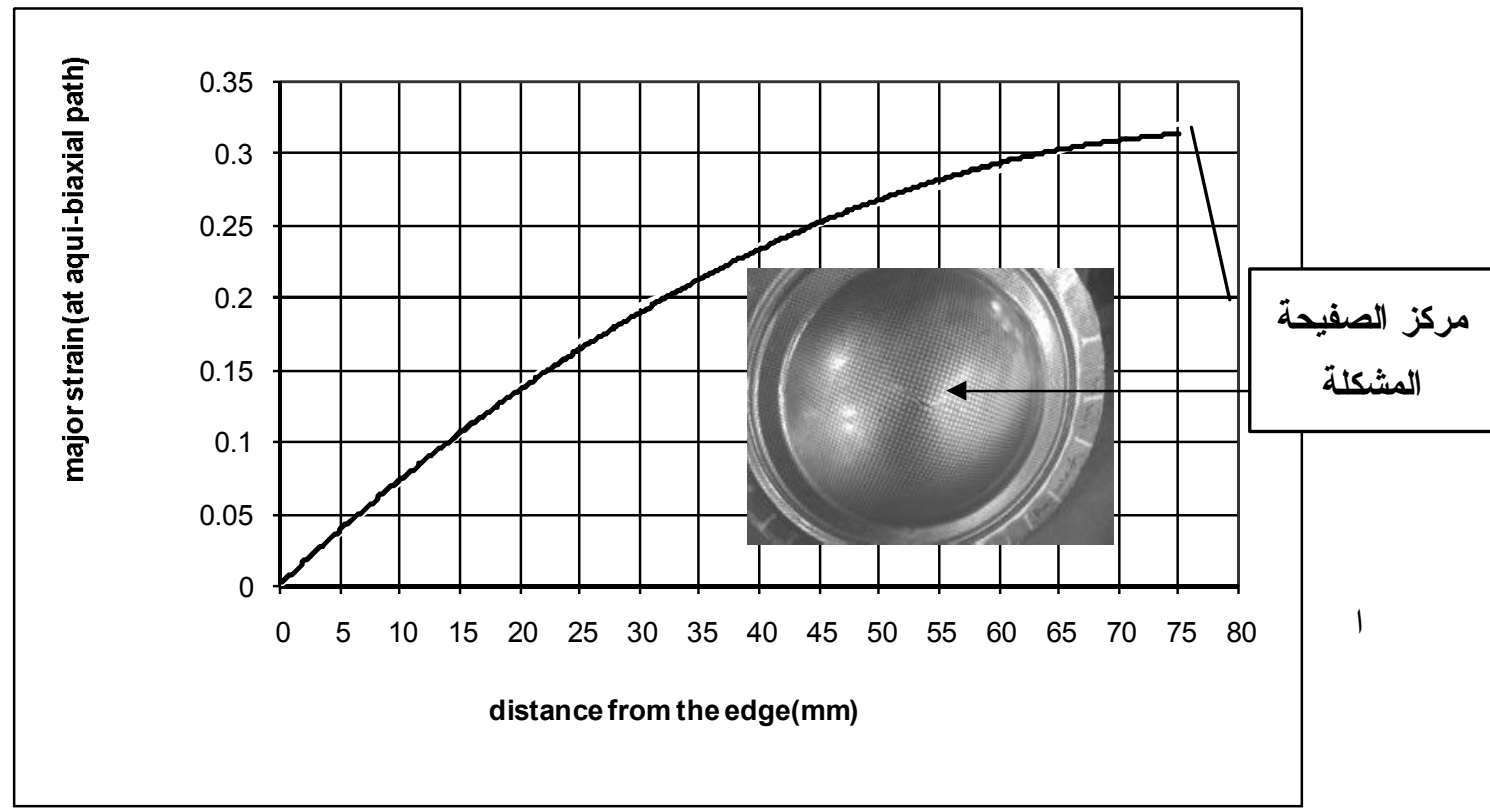

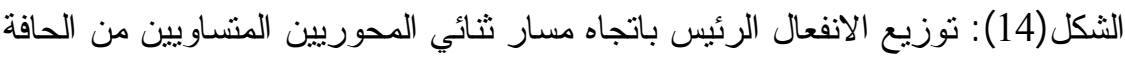
الى المركز بطريقة النتكيل بالنفخ الهيدروليكي

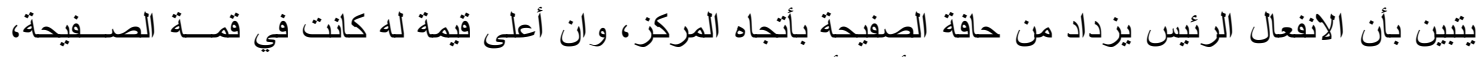

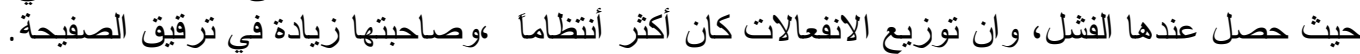

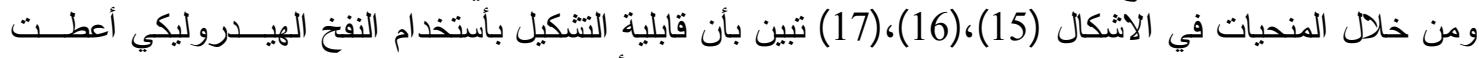

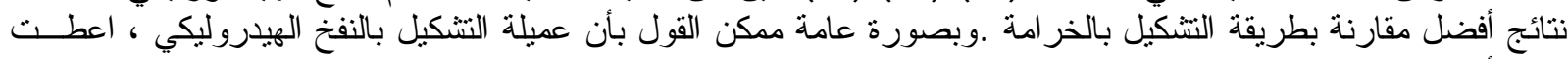

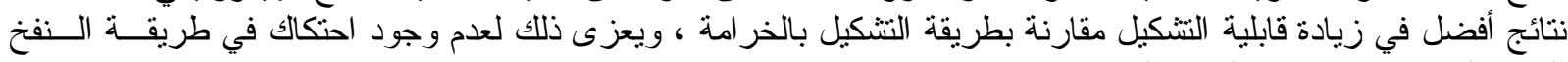
العيدروليكي ووجوده في طريقة فيلة الخر امة. 


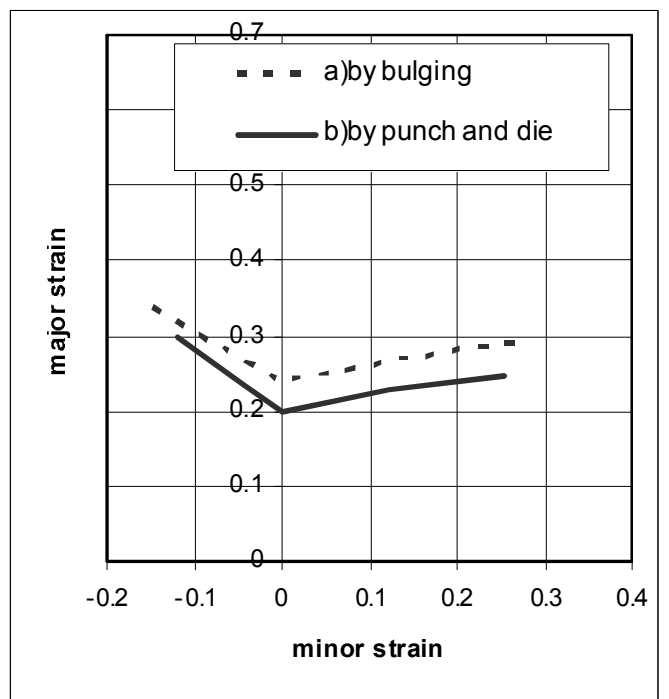

الثكل(15): مقارنة بين منحني حد النشكيل

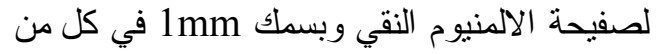
(a

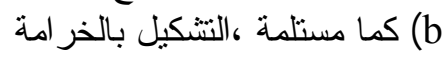

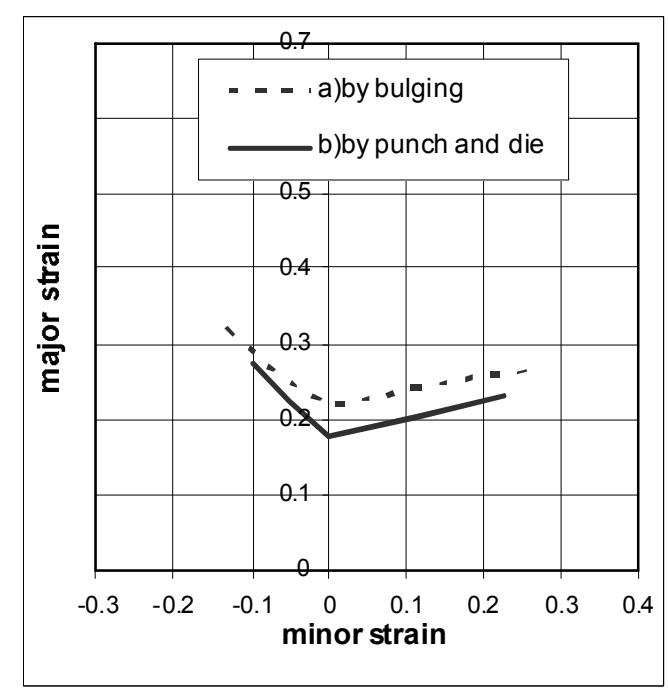

الثكل(16): مقارنة بين منحني حد النتكيل لصفيحة

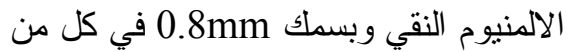

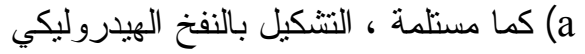

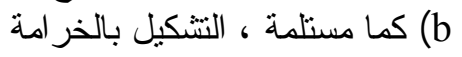

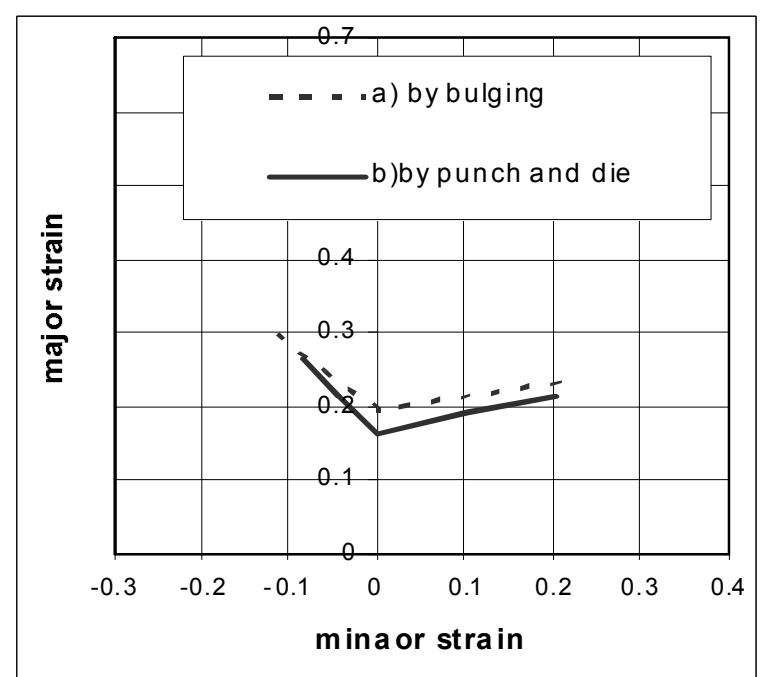

الثكل(17): مقارنة بين منحني حد النتكيل لصفيحة الالمنيوم النقي وبسمك 0.6mm في كل من

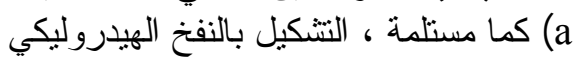

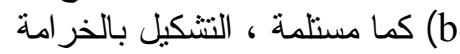


1. Petar A., et.al., " Materials Selection and Design ", Metal Handbook, The volume was prepared under the direction of the ASM Handbook Committee, Vol.20, pp709-713, 1997.

2. Marciniak,A.,Durcan,J.L," Mechanics of Sheet Metal Forming " ,Butter Worth-Heineman,2002

3. Keeler S.P. and Backofen W.A., " Plastic Instability and Fracture in Sheets Stretched Over Rigid Punches ", Transactions of The ASM,Vol. 56, 25-48. 1963

4. Keeler.S.P, " Circular Grid System, A Valuable Aid For Evaluating Sheet Metal Formability ", Society of Automotive Engineers Technical Paper, No.680093, 1968.

5. Goodwin, G.M., " Application of Strain Analysis to Sheet Metal Forming Problems in the Press Shop ", Society of Automotive Engineers, technical paper No. 680093, 1968

6. Hecker.S.S., " Experimental Studies of Sheet Stretchability " Proc. of Symp. on Formability Analysis-Modeling and E., cperimentation, Chicago, IL, p. 1501977

7. Padwal, S.B. and Chaturvedi, R.C., " Prediction of Forming Limits Using Hosford's Modified Yield Criterion ", Int. J. Mech. Sci. vol. 34, No. 7, pp. 541-547, 1992.

8. Aghaie,K., M.Mahmudib.R., " The Effect of Preheating on The Formability of Al-Fe-Si alloy Sheet ", Journal of Materials Processing Technology 169,38-43, 2005.

9. Gupta-A-K, Kumar, D.R, " Formability of Galvanized Interstitial-Free Steel Sheet ' ,Journal of Material Processing Technology, 172,225-237, 2006.

10. Ali.W.J., Edress, A-O., " Theoretical Determination of Forming Limit Diagram for Steel, Brass and Aluminum Alloy Sheet",Al-Rafidian Engineering Vol.15,No.1, 2007.

11. Kobayshi, S., and H.Kim, J. " Determination Analysis of Ax symmetric Sheet Metal Forming Processes by The Rigid-Plastic Finite Element Method ", General Motors Research Laboratories, 1980.

12. Dr. Banabic, T. and Comsa, D-S., " Closed-Forme Solution For Bulging Through Elliptical Dies ", Journal of Materials Processing Technology 115,38-86,2001.

13. Isek, H., " An approximate Deformation Analysis and FEM Analysis for The Increment Bulging of Sheet Metal Using a Spherical Roller ", Journal of Materials Processing Technology 111, 150154,2001

14. J. Slota, E-Spisak, " Determination of Flow Stress by The Hydraulic Bulge Test ", Metabk47, 13$17,2008$.

15. Anas O.A. AL-Shammery, " Study of Factors Affecting The Determination of Forming Limit Diagram For Sheet Metals ", University of Mosul, Mechanical Engineering Department, 2005.

16. Haroldo B., Campos, Marilen Carmen, Butuc, Jose Joaquim Gracio and Joao Rocha, " Theatrical and Experimental Determination of The Forming Limit Diagram For The AISI304 Stainless Steel"Journal of Materials Processing Technology 179,56-60, 2006.

17. Hecker, S.S., " A Simple Forming Limit Curve Technique and Result on Aluminum Alloys ", Sheet Metal Forming and Formability Proceedings of the $7^{\text {th }}$. Biennial Congress of IDDRG, pp5.1 to 5.8, Amsterdam, October, 1972.

18. Fawzi M.A. " Formability in Sheet Metals by Finite Element Method ", Ph.D. Thesis , Mechanical Department, University of Mosul, 2006

19. William F.Hosford and Robert M. Caddell, "Metal Forming", Prentic-Hall, Inc, Englewood clitts, NJ07632, 1983.

$$
\text { تم اجراء البحث في كلية الهنسسة - جامعة الموصل }
$$

